\title{
Knowledge of malaria prevention among pregnant women and female caregivers of under-five children in rural southwest Nigeria
}

Ayodeji M. Adebayo, Oluwaseun O. Akinyemi, Eniola O. Cadmus

Introduction: The morbidity and mortality from malaria is still unacceptably high in the developing countries, especially among the vulnerable groups like pregnant women and under-five children, despite all control efforts. The knowledge about the preventive measures of malaria is an important preceding factor for the acceptance and use of malaria preventive measures like Insecticide Treated Nets (ITN) by community members. Therefore, this study assessed the knowledge of malaria prevention among caregivers of under-five children and pregnant women in a rural community in Southwest Nigeria. Methodology: This is part of a larger malaria prevention study in rural Southwest Nigeria. A descriptive cross-sectional survey was conducted among pregnant women and caregivers of under-five children in Igbo-Ora, a rural town in Southwest Nigeria using a semistructured, interviewer-administered questionnaire. Information was obtained on knowledge of malaria prevention and overall composite scores were computed for knowledge of malaria prevention and ITN use. Data were analyzed using SPSS version 16. Associations between variables were tested using Chi-square with the level of statistical significance set at $5 \%$. Results: Of the 631 respondents, $84.9 \%$ were caregivers of underfive children and $67.7 \%$ were married. Mean age was $27.7 \pm 6.3$ years with $53.4 \%$ aged between 20 and 29 years. Majority (91.1\%) had at least primary school education and $60.2 \%$ were traders. Overall, $57.7 \%$ had poor knowledge of malaria prevention. A good proportion (83.5\%) were aware of the use of ITN for malaria prevention while $30.6 \%$ had poor knowledge of its use. Respondents who were younger ( $<30$ years), had at least primary education and earn $<10,000 /$ per month had significantly poor knowledge of ITN use in malaria prevention. Majority $(60.0 \%)$ respondents had poor attitude regarding use of ITNs. Conclusion: This study showed that the knowledge of malaria prevention is still low among under-five caregivers and pregnant women in rural Southwest Nigeria despite current control measures. There is need for concerted health education intervention to improve the knowledge of rural dwellers regarding malaria prevention including the use of ITN. This will go a long way to improve the reported low level of ownership and utilization of ITN in the rural areas. 
23 seunakinyemi@hotmail.com

$24+2348035020136$ Ibadan, Nigeria Nigeria

\section{Original Article}

\section{Five Children in Rural Southwest Nigeria}

Keywords: Malaria prevention, Under-five caregivers, Pregnant women, Insecticide treated net, Rural dwellers, Nigeria Ayodeji M. Adebayo1, Oluwaseun O. Akinyemi²* and Eniola O. Cadmus ${ }^{1}$

${ }^{1}$ Department of Preventive Medicine and Primary Care, College of Medicine, University of Ibadan,

${ }^{2}$ Department of Health Policy and Management, College of Medicine, University of Ibadan, Ibadan,

*Corresponding author: Dr. Oluwaseun O. Akinyemi

21 Address: Department of Health Policy and Management, Faculty of Public Health, College of

22 Medicine, University of Ibadan, Ibadan, Nigeria 


\section{Introduction}

Malaria is a completely preventable disease; however, about 3.4 billion people are at risk of the disease globally with 1.2 billion people at high risk (World Health Organization 2013). In 2012, malaria was responsible for the death of approximately 482,000 under-five children even though an estimated 136 million Insecticide Treated Nets (ITNs) were distributed to endemic countries the same year (World Health Organization 2013). Thus, malaria is still a major public health concern particularly in subSaharan Africa and other parts of the developing world (Pluess et al. 2009; Pluess et al. 2010). In Nigeria, malaria is responsible for around $60 \%$ of the out-patient visits to health facilities, $30 \%$ of childhood death, $25 \%$ of death in children under one year and $11 \%$ of maternal deaths (National Population Commission 2008; Noland et al. 2014). Similarly, about 70\% of pregnant women suffer from malaria; contributing to maternal anemia, low birth weight, still births, abortions and other pregnancy-related complications (Federal Ministry of Health Abuja 2005). The financial loss due to malaria is estimated to be about 132 billion Naira (\$797 million) annually in form of treatment costs, prevention costs, loss of man-hours (Noland et al. 2014; World Health Organization 2012).

Malaria, a debilitating febrile and life threatening illness, is caused by a parasite called Plasmodium. Its route of transmission still remains bites from infected female anopheles mosquitoes. Environmental factors and behavioral patterns of vectors and human populations combine to provide favorable conditions for malaria transmission (Boutin et al. 2005). Proven effective options to reduce morbidity and mortality include early diagnosis, combined with prompt effective therapy and malaria prevention through reduction of human-vector contact, especially with the use of ITNs (World Health Organization 2007). Perceptions about malaria illness, particularly households' perceived susceptibility and beliefs about the seriousness of the disease are important preceding factors for decision-making concerning preventive and curative actions (Rakhshani et al. 2003). The understanding of the possible causes, modes of transmission, and individuals' preference and decision about adoption of preventive and control measures vary from community to community and among individual households (Adongo et al. 2005). There have been a considerable number of reports about knowledge, attitudes, and practices relating to malaria and its control from different parts of Africa. These reports concluded that misconceptions concerning malaria still exist and that practices for the control of malaria have been unsatisfactory (Ahorlu et al. 1997; Alaii et al. 2003; Laver et al. 2001; Obol et al. 2011).

Achieving sustainable control of the disease depend on extensive public health promotional programs which focus on current and proven methods of malaria prevention and management. While much is 
57 known about vector biology and behaviour and the malaria parasites, the importance of human behaviour

58 in malaria transmission has not been critically evaluated. Studies focusing on the current practices of 59 malaria prevention and treatment options in the population are sparse. Thus, it is expedient to evaluate 60 current knowledge of malaria prevention practices and management options as well as the uptake of the 61 management options. In most high-burden countries (including Nigeria), ITN coverage is still below 62 agreed targets (Minja \& Obrist 2005). This may be related to the perception of its use among the 63 community members. The knowledge about the preventive measures of malaria is an important 64 preceding factor for the acceptance and use of ITN for malaria control by the community members (Minja 65 et al. 2001). Therefore, this study assessed the knowledge of malaria prevention with emphasis on 66 knowledge of ITN use among pregnant women and caregivers of under-five children in Igbo-Ora.

67 Igbo-Ora is a rural community in Ibarapa Central Local Government Area (LGA) of Oyo State, 68 Southwest Nigeria. The main towns in the LGA are Igboora and Idere. Igboora is the larger town with a 69 population of 60,000 people. The LGA has ten political wards with seven located in Igboora, the study 70 site. Igbo-Ora is located about $128 \mathrm{~km}$ from Lagos - the Nigerian economic capital. The predominant 71 language in the study area is Yoruba. However, migrant farm labourers from the republic of Benin, Togo 72 and Ghana reside in the LGA. There are some nomadic Fulanis who live in settlements around the town.

73 Igbo-Ora is further divided into six census areas comprised of 62 enumeration areas, each with an average 74 population of 600 people. Furthermore, each enumeration area is divided into compounds and each 75 compound has about 100 women in the reproductive age group. 
77 Methodology

78 The study population is made up of pregnant women in their reproductive age (15-49 years) and female 79 caregivers of under-five children, who have lived in the community for at least one year. For the purpose 80 of this study, caregivers may include mothers and female guardians of under-five children.

81 A community-based descriptive cross-sectional survey was carried out using a multistage cluster 82 sampling technique. Three enumeration areas were selected by simple random sampling through 83 balloting from each of the six census areas. Subsequently, two compounds were selected from each of 84 these enumeration areas by balloting. A minimum sample size of 126 was estimated using Leslie and 85 Kish formula for approximating sample size for cross sectional study. This was multiplied by a factor of 86 two to adjust for clustering effect. A total of 631 eligible and consenting caregivers of under-five children 87 and pregnant women in the households within the selected compounds were then interviewed. All the 88 people who were approached consented to participate in the study.

89 A pre-tested semi-structured interviewer-administered questionnaire was used to collect information on 90 the socio-demographic characteristics of respondents, knowledge of malaria prevention and knowledge 91 of ITN use; and perception of ITN use in malaria prevention. Knowledge about malaria prevention and 92 ITN use were assessed through a six-point score each. A point was given to each correct answer 0 to 93 wrong answer. The mean knowledge score was used to dichotomize knowledge scores. Knowledge about 94 malaria prevention was categorized into "good" (4-6) and "poor" (0-3) while scores of 0-4 were deemed 95 poor and 5-6 were considered good for knowledge of ITN use for malaria prevention. The questionnaire 96 was translated to Yoruba in order to enable proper understanding by respondents and back-translated to 97 English to ensure that the original meaning was retained. Questionnaire administration was done by four 98 trained research assistants whose minimum educational qualification was National Certificate in 99 Education (NCE) or Ordinary National Diploma (OND) and were fluent in speaking the local dialect. 100 The questionnaire was pre-tested in Idere, the second main town in Ibarapa Central LGA.

101 Data were analyzed using the Statistical Package for Social Sciences (SPSS version 16). Associations 102 between variables were tested using Chi-square with the level of statistical significance set at 5\%. The 103 raw data for this study may be accessed through: https://docs.google.com/a/cartafrica.org/file/d/0B62N6G90gxJZNzdIT05NQ2w1QWs/edit . 
105 The Oyo State Ethical Review Committee, Ministry of Health, Ibadan gave ethical clearance and approval for this study (reference number: AD 13/479/76). Informed verbal consent was also gotten from individual research participant before data collection. The respondents were also reminded of their right to decline to take part in the study as well as to withdraw any time during the interview. Confidentiality was assured and maintained throughout the study. The importance of the study was explained to participants as well as how their participation in the study will contribute towards malaria prevention programing in Nigeria.

\section{Results}

Figure 1 shows the distribution of respondents. A total of 631 respondents were interviewed, out of whom $536(84.9 \%)$ were caregivers of under-five children. The socio-demographic characteristics of respondents are shown in Table 1 . The mean age of respondents was $27.7 \pm 6.3$ years with about 53\% aged between 20 and 29 years. More than 90\% have at least primary education while trading (60.2\%) was the most common occupation among respondents. About $70 \%$ were married and living with their spouses. A greater proportion, (71.9\%) of respondents were either in or from a monogamous relationship. About $60 \%$ of respondents have 2 children or less while almost all $(97.5 \%)$ have 2 or less under-five children. About 97\% were from the Yoruba ethnic affiliation and more than half, (57.6\%) were Muslims. Most respondents, $64.7 \%$ earned less than $\$ 10,000$ (\$59.4) monthly. Only 8.4\% earned $\$ 30,000$ (\$178.2) and above. The median average income was $\$ 5000$ (\$29.7); range: $\$ 1000-\$ 150,000$.

Table 2 revealed that less than half of respondents $(42.3 \%)$ had good knowledge of malaria prevention. Table 3 shows respondents' knowledge regarding methods of malaria prevention. About $85 \%, 82 \%$, and $75 \%$ knew that malaria could be prevented through keeping the environment clean, clearing of bushes around houses and use of ITN respectively. However, approximately $77 \%$ and $82 \%$ of respondents felt taking native concoction and using malaria prophylaxis respectively could prevent occurrence of malaria infection.

Nearly $84 \%$ of participants had heard of ITN while almost $70 \%$ had good knowledge of the use of ITN in malaria prevention (Table 4). Regarding the use of ITN in malaria prevention, about $80 \%$ knew that ITN is useful in malaria prevention and over three-quarters understood that it could kill mosquito (Table 5).

Table 6 shows attitude of under-five caregivers and pregnant women regarding ITN and its use. Roughly $63 \%$ of respondents did not agree that window/door nets was better or the same as ITN. Similarly, 61\% 
135 of participants disagreed with the statement that "ITN does not make any difference in malaria 136 prevention". Well over half of participants (56.1\%) agreed that "either one uses mosquito net or not, 137 those that will be infected with malaria will definitely have it". Majority were indifferent as to whether

138 ITN causing irritation, heat rash, cough, vomiting in pregnancy, miscarriage, mortality in children and 139 bad odor.

140 Table 7 demonstrated that mothers and under-five caregivers with higher educational status, who were 141 civil servants, with higher income, and married had good knowledge of malaria prevention $(\mathrm{p}<0.05)$. 142 Similarly respondents who earned high income and were married had significantly better knowledge of 143 ITN use (Table 8).

144

\section{Discussion}

146 This study was conducted to assess knowledge of malaria prevention with emphasis on ITN use among 147 female caregivers of under-five children and pregnant women in Igbo-Ora, a rural community in 148 Southwest Nigeria. The overall knowledge of malaria prevention practices among majority of the 149 respondents was found to be poor. This finding agrees with the submissions of Fawole and Onyeaso 150 (2008) who showed that even among health workers in Ibadan, Southwest Nigeria, knowledge of malaria 151 preventive strategies was poor. However, this finding is at variance with the conclusions of Adegun et 152 al (2011) and Oyewole \& Ibidapo (2007) who showed that the general knowledge about malaria 153 prevention among urban residents in Southwest Nigeria was good. The knowledge picture seen among 154 respondents in this study could be as a result of lack of exposure to health education messages regarding 155 156 157 malaria prevention, being rural dwellers, or respondents' poor health seeking behavior. For those who had exposure to health messages in health facilities, some might find it difficult to understand malaria prevention information given during antenatal and postnatal clinics. This might be due partly to inappropriate means of communication and delivery of these messages by the health workers in addition to the respondents' low level of education. Respondents' level of education was found to be significantly associated with knowledge of malaria prevention. Therefore, achieving malaria prevention, just like any other health message, depend on the level of education of respondents among other reasons.

162 Furthermore, relatively high proportions of the respondents in our study knew that use of antimalarial 163 prophylaxis in pregnancy, clearing of bushes around the house and keeping the environment clean were 164 part of malaria prevention strategies. The knowledge of the importance of prophylaxis for malaria 
165 prevention may be a function of the fact that they had benefited from intermittent preventive treatment 166 (IPT) during index or previous pregnancies during which they might have had health education on the

167

168

169

170

171

172

173

174

175

176

177

178

179

180

181

182

183

184

185

186

187

188

189

190

191

192

193

194 issue. However, other studies from Nigeria (Falade et al. 2006; Okeke et al. 2006) and Tanzania (Comoro et al. 2003) have documented that gaps still exist in the knowledge of causation and treatment of malaria in rural areas and that these gaps have serious public health implications.

Most of these rural respondents still exhibited some myths and misconceptions about malaria prevention. Drinking of native concoction and use of antibiotics for malaria treatment were some of the erroneous believes reported. The finding on the use native concoction by pregnant women in Nigeria is corroborated by Fakeye and colleagues (2009) who advised that questions on herbal drug use should be routinely asked by health workers during antenatal care to forestall dangerous drug interactions. Herbal preparations, though not medically recommended for the treatment of diseases like malaria is an innate traditional practice which is considered normal by people because of a deep cultural attachment. Inadequate information from health workers and respondents' low level of education could also contribute to the misconceptions of malaria treatment. Continuous efforts at providing necessary information by relevant health organizations are needed to control and prevent incidence of malaria in the general public.

More than two-thirds of the respondents had good knowledge of ITN use for malaria prevention. Awosan et al (2013), in a study to determine the prevalence and barriers to the use of insecticide treated nets among pregnant women attending ante-natal clinic in a Specialist Hospital at Sokoto, reported similar finding. However, in a hospital-based study about awareness of ITN use in Abeokuta, Southwest Nigeria, Runsewe-Abiodun et al (2012) reported low awareness and linked this to the low utilization among the pregnant women interviewed. The current ongoing aggressive public health campaign which involves mass distribution of ITNs at PHC centers could account for the high awareness noted in this study. However, some respondents had poor attitudes and misconceptions about the use of ITNs. Respondents' attitudes may have a strong implication on ownership and utilization of ITNs (Onwujekwe et al. 2005).

\section{Conclusion and recommendations}

Despite concerted efforts at malaria control nationwide, knowledge of malaria prevention was below average among rural caregivers of under-five children and pregnant women in the study area. Myths and misconceptions about malaria prevention is still prevalent. There is a need for a concerted health education intervention to improve the knowledge of rural dwellers regarding malaria prevention 
195 especially with the use of Insecticide Treated Net. Continuous efforts at providing necessary information 196 by relevant health organizations are needed to control and reduce incidence of malaria in the general 197 public. 
199

200

201

202

203

204

205

206

207

208

209

210

211

212

213

214

215

216

217

218

219

220

221

222

223

224

225

226

227

228

229

230

231

232

233

234

235

236

237

\section{References}

Adegun JA, Adegboyega JA, and Awosusi AO. 2011. Knowledge and the preventive strategies of

Malaria among Migrant Farmers in Ado-Ekiti Local Government Area of Ekiti State, Nigeria. American Journal of Scientific and Industrial Research, Science Hub.

Adongo PB, Kirkwood B, and Kendall C. 2005. How local community knowledge about malaria affects insecticide-treated net use in northern Ghana. Tropical Medicine \& International Health 10:366-378.

Ahorlu CK, Dunyo SK, Afari EA, Koram KA, and Nkrumah FK. 1997. Malaria-related beliefs and behaviour in Southern Ghana: Implications for treatment, prevention and control. Tropical Medicine \& International Health 2:488-499.

Alaii JA, Van den Borne H, Kachur SP, Shelley K, Mwenesi H, Vulule JM, Hawley WA, Nahlen BL, and Phillips-Howard PA. 2003. Community reactions to the introduction of permethrintreated bed nets for malaria control during a randomized controlled trial in western Kenya. The American journal of tropical medicine and hygiene 68:128-136.

Awosan KJ, Ibrahim MTO, Alayande MO, Isah BA, Yunusa E, and Mahmud MB. 2013. Prevalence and barriers to the use of insecticide treated nets among pregnant women attending ante-natal clinic at Specialist Hospital Sokoto, Nigeria. Journal of Public Health 5:416-420.

Boutin J-P, Pradines B, Legros F, Rogier C, and Migliani R. 2005. Epidemiology of malaria. La Revue du praticien 55:833-840.

Comoro C, Nsimba S, Warsame M, and Tomson G. 2003. Local understanding, perceptions and reported practices of mothers/guardians and health workers on childhood malaria in a Tanzanian district - implications for malaria control. Acta tropica 87:305-313.

Fakeye TO, Adisa R, and Musa IE. 2009. Attitude and use of herbal medicines among pregnant women in Nigeria. BMC Complementary and Alternative Medicine 9:53.

Falade CO, Ogundiran MO, Bolaji MO, Ajayi IO, Akinboye DO, Oladepo O, Adeniyi JD, and Oduola AM. 2006. The influence of cultural perception of causation, complications, and severity of childhood malaria on determinants of treatment and preventive pathways.

International quarterly of community health education 24:347-363.

Fawole AO, and Onyeaso NC. 2008. Perception and practice of malaria prophylaxis in pregnancy among primary health care providers in Ibadan, Nigeria. West African journal of medicine 27:9296.

Federal Ministry of Health Abuja. 2005. National Malaria Control Programme annual report. Abuja: Federal Ministry of Health, Nigeria.

Laver SM, Wetzels J, and Behrens RH. 2001. Knowledge of malaria, risk perception, and compliance with prophylaxis and personal and environmental preventive measures in travelers exiting Zimbabwe from Harare and Victoria Falls International airport. Journal of travel medicine 8:298-303.

Minja H, and Obrist B. 2005. Integrating local and biomedical knowledge and communication: experiences from KINET project in southern Tanzania. Human Organization 64:157-165. 
238 Minja H, Schellenberg JA, Mukasa O, Nathan R, Abdulla S, Mponda H, Tanner M, Lengeler C, and

239 Obrist B. 2001. Introducing insecticide-treated nets in the Kilombero Valley, Tanzania: the

240 relevance of local knowledge and practice for an Information, Education and Communication (IEC)

241 campaign. Tropical Medicine \& International Health 6:614- 623.

242 National Population Commission. 2008. Nigeria demographic and health survey 2008. Nigeria and

243 ICF Macro.

244 Noland GS, Graves PM, Sallau A, Eigege A, Emukah E, Patterson AE, Ajiji J, Okorofor I, Oji OU,

245 and Umar M. 2014. Malaria prevalence, anemia and baseline intervention coverage prior to mass

246 net distributions in Abia and Plateau States, Nigeria. BMC infectious diseases 14:168.

247 Obol J, David Lagoro K, and Christopher Garimoi O. 2011. Knowledge and Misconceptions about

248 Malaria among Pregnant Women in a Post-Conflict Internally Displaced Persons' Camps in Gulu

249 District, Northern Uganda. Malaria research and treatment 2011.

250 Okeke TA, Uzochukwu BS, and Okafor HU. 2006. An in-depth study of patent medicine sellers'

251 perspectives on malaria in a rural Nigerian community. Malaria Journal 5:97.

252 Onwujekwe O, Uzochukwu B, Ezumah N, and Shu E. 2005. Increasing coverage of insecticide-

253 treated nets in rural Nigeria: implications of consumer knowledge, preferences and

254 expenditures for malaria prevention. Malaria Journal 4:29.

255

256

257

258

259

260

261

262

263

264

265

266

267

268

269

270

271

272

273

Oyewole IO, and Ibidapo AC. 2007. Attitudes to malaria, prevention, treatment and management strategies associated with the prevalence of malaria in a Nigerian urban center. African Journal of Biotechnology 6:2424-2427.

Pluess B, Mueller I, Levi D, King G, Smith TA, and Lengeler C. 2009. Malaria-a major health problem within an oil palm plantation around Popondetta, Papua New Guinea. Malar $J$ 8:56.

Pluess B, Tanser FC, Lengeler C, and Sharp BL. 2010. Indoor residual spraying for preventing malaria. Cochrane Database Syst Rev 4.

Rakhshani F, Ansari MA, Alemi R, and Moradi A. 2003. Knowledge, perceptions and prevention of malaria among women in Sistan va Baluchestan, Islamic Republic of Iran. Eastern Mediterranean health journal 9:248-256.

Runsewe-Abiodun T, Iyabo IA, and Christy SA. 2012. Awareness and knowledge about Insecticide

Treated Nets (ITNs) amongst pregnant mothers in Ogun State, Western- Nigeria: a descriptive cross sectional study. Edu Res J 2:138-145.

World Health Organization. 2007. Insecticide-treated mosquito nets: a WHO position statement. Geneva: WHO.

World Health Organization. 2012. Progress \& Impact Series: Focus on Nigeria.

World Health Organization. 2013. Factsheet on the World Malaria Report 2013. Available at http://www.who.int/malaria/media/world_malaria_report_2013/en/(accessed 9 November 2014). 
Figure 1 (on next page)

Distribution of respondents 


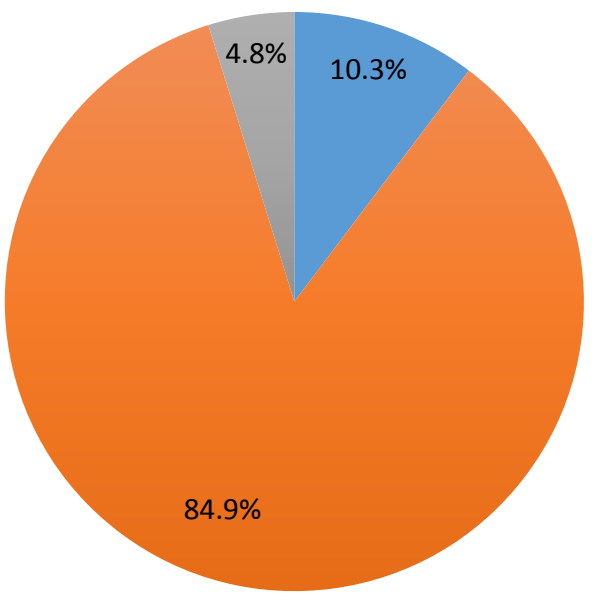

- Pregnant

Under-five caregiver Both 


\section{Table $\mathbf{1}$ (on next page)}

Socio-demographic characteristics of the respondents 


\section{Tables}

3 Table 1: Socio-demographic characteristics of the respondents $(N=631)$

\begin{tabular}{|c|c|c|}
\hline Socio-demographic characteristics & Frequency & Percent \\
\hline \multicolumn{3}{|l|}{ Age group } \\
\hline$<20$ & 36 & 5.7 \\
\hline $20-29$ & 337 & 53.4 \\
\hline $30-39$ & 230 & 36.5 \\
\hline$\geq 40$ & 28 & 4.4 \\
\hline \multicolumn{3}{|l|}{ Level of education } \\
\hline No formal education & 56 & 8.9 \\
\hline Primary & 206 & 32.6 \\
\hline Secondary & 275 & 43.6 \\
\hline Tertiary & 94 & 14.9 \\
\hline \multicolumn{3}{|l|}{ Occupation } \\
\hline Trading & 380 & 60.2 \\
\hline Civil servant & 78 & 12.4 \\
\hline Farming & 15 & 2.4 \\
\hline Unemployed & 158 & 25 \\
\hline \multicolumn{3}{|l|}{ Income (\#) } \\
\hline$<1,000$ & 408 & 64.7 \\
\hline $10,000-19,000$ & 107 & 17.0 \\
\hline $20,000-29,000$ & 63 & 10.0 \\
\hline$\geq 30,000$ & 53 & 8.4 \\
\hline \multicolumn{3}{|l|}{ Marital status } \\
\hline Single & 30 & 4.8 \\
\hline Co-habiting & 85 & 13.5 \\
\hline Married, living together & 440 & 69.7 \\
\hline Married, living alone & 67 & 10.6 \\
\hline Separated & 8 & 1.3 \\
\hline Divorced & 1 & 0.2 \\
\hline \multicolumn{3}{|l|}{ Family Type } \\
\hline Monogamous & 454 & 71.9 \\
\hline Polygamous & 177 & 28.1 \\
\hline \multicolumn{3}{|l|}{ Total number of children } \\
\hline $0-2$ & 380 & 60.2 \\
\hline $3-4$ & 228 & 36.1 \\
\hline$\geq 5$ & 23 & 3.7 \\
\hline \multicolumn{3}{|l|}{ Number of $U-5$ children } \\
\hline $0-2$ & 615 & 97.5 \\
\hline $3-4$ & 16 & 2.5 \\
\hline \multicolumn{3}{|l|}{ Ethnic group } \\
\hline Yoruba & 611 & 96.8 \\
\hline Igbo & 7 & 1.1 \\
\hline Hausa & 5 & 0.8 \\
\hline Others & 8 & 1.3 \\
\hline \multicolumn{3}{|l|}{ Religion } \\
\hline Christianity & 268 & 42.5 \\
\hline Islam & 363 & 57.6 \\
\hline
\end{tabular}


Table 2 (on next page)

Respondents' knowledge score of malaria prevention 
2 Table 2: Respondents' knowledge score of malaria prevention

\begin{tabular}{lcc}
\hline Knowledge score (0-6) & Frequency & Percentage \\
\hline Good (4-6) & 269 & 42.3 \\
Poor (0-3) & 364 & 57.7 \\
\hline
\end{tabular}

$3 \quad$ Mean $=3.4 \pm 1.2$

4 


\section{Table 3(on next page)}

Respondents' distribution of knowledge about methods of malaria prevention 
2 Table 3: Respondents' distribution of knowledge about methods of malaria prevention*

\begin{tabular}{|c|c|c|}
\hline $\begin{array}{l}\text { Methods of malaria } \\
\text { prevention }\end{array}$ & Yes $(\%)$ & No (\%) \\
\hline Drinking native concoction & $485(76.9)$ & $146(23.1)$ \\
\hline $\begin{array}{l}\text { Keeping our environment } \\
\text { clean }\end{array}$ & $534(84.6)$ & $97(15.4)$ \\
\hline $\begin{array}{l}\text { Clearing of bushes around } \\
\text { the house }\end{array}$ & $516(81.8)$ & $115(18.2)$ \\
\hline Use of antibiotics & $300(47.5)$ & $331(52.5)$ \\
\hline Use of ITN & $473(75.0)$ & $158(25.0)$ \\
\hline $\begin{array}{l}\text { Use of antimalarial } \\
\text { prophylaxis }\end{array}$ & $519(82.3)$ & $112(17.7)$ \\
\hline
\end{tabular}

3 *Multiple response

4 


\section{Table 4(on next page)}

Respondents' awareness of ITN and knowledge score of ITN use in malaria prevention 
2 Table 4: Respondents' awareness of ITN and knowledge score of ITN use in malaria prevention

\begin{tabular}{lcc}
\hline Awareness & Number & Percent \\
\hline Yes & 527 & 83.5 \\
No & 104 & 16.5 \\
\hline Knowledge score of ITN use in malaria (0-6) & & \\
Good (5-6) & 438 & 69.4 \\
Poor (0-4) & 193 & 30.6 \\
Total & 631 & 100.0 \\
\hline
\end{tabular}

$3 \quad$ Mean knowledge score $=4.4 \pm 1.7$

4 


\section{Table 5 (on next page)}

Respondents' distribution of knowledge about the use of ITN in malaria prevention 
2 Table 5: Respondents' distribution of knowledge about the use of ITN in malaria prevention*

\begin{tabular}{lll}
\hline Knowledge if ITN use & Yes (\%) & No (\%)
\end{tabular}

Keep flies away

$409(64.8)$

$222(35.2)$

Keep rats away

$171(27.1)$

$460(72.9)$

Fishing

$152(24.1)$

$479(75.9)$

Prevents mosquito bite

$520(82.4)$

$111(17.6)$

Useful in malaria prevention

$503(79.7)$

$128(20.3)$

Kills mosquitoes

$476(75.4)$

155 (24.6)

3 *Multiple response

4 
Table 6(on next page)

Respondents' attitude towards ITN and its use 
2 Table 6: Respondents' attitude towards ITN and its use

\begin{tabular}{|c|c|c|c|}
\hline & Agree (\%) & Don't know (\%) & Disagree (\%) \\
\hline It is the same as window/door net & $97(15.4)$ & $134(21.2)$ & $400(63.4)$ \\
\hline $\begin{array}{l}\text { It does not make any difference in } \\
\text { malaria prevention }\end{array}$ & $103(16.3)$ & $144(22.8)$ & $384(60.9)$ \\
\hline ITN smells badly & $43(6.8)$ & $451(71.5)$ & $137(21.7)$ \\
\hline ITN causes irritation & $20(3.2)$ & $469(74.3)$ & $142(22.5)$ \\
\hline ITN causes heat rashes & $21(3.3)$ & $466(73.9)$ & $144(22.8)$ \\
\hline ITN causes cough/illness & $10(1.6)$ & $465(73.7)$ & $156(24.7)$ \\
\hline ITN causes nightmares/bad dreams & $5(0.8)$ & $459(72.7)$ & $167(26.5)$ \\
\hline The chemical in ITN can kill children & $3(0.5)$ & $450(71.4)$ & $178(28.2)$ \\
\hline $\begin{array}{l}\text { ITN use in pregnancy can cause } \\
\text { miscarriage }\end{array}$ & $2(0.3)$ & $457(72.4)$ & $172(27.3)$ \\
\hline $\begin{array}{l}\text { ITN can cause vomiting in pregnant } \\
\text { women }\end{array}$ & $10(1.6)$ & $464(73.5)$ & $157(24.9)$ \\
\hline ITN cannot kill mosquitoes & $26(4.1)$ & $338(53.6)$ & $267(42.3)$ \\
\hline ITN is not readily available & $137(21.7)$ & $389(61.6)$ & $105(16.6)$ \\
\hline ITN is expensive & $157(24.9)$ & $419(66.4)$ & $55(8.7)$ \\
\hline Window nets/door nets are better & $35(5.5)$ & $212(33.6)$ & $384(60.9)$ \\
\hline $\begin{array}{l}\text { Ordinary net (without insecticide) is } \\
\text { better/preferable }\end{array}$ & $40(6.3)$ & $202(32.0)$ & 389 (61.6) \\
\hline $\begin{array}{l}\text { Either you use mosquito net or not } \\
\text { those who will have malaria will still } \\
\text { have it }\end{array}$ & $354(56.1)$ & $121(19.2)$ & $156(24.7)$ \\
\hline
\end{tabular}

3 


\section{Table 7 (on next page)}

Association between respondent characteristics and knowledge of malaria prevention 
2 Table 7: Association between respondent characteristics and knowledge of malaria prevention

\begin{tabular}{|c|c|c|c|c|}
\hline \multirow[t]{2}{*}{ Variables } & \multicolumn{2}{|c|}{$\begin{array}{c}\text { Knowledge of Malaria } \\
\text { Prevention }\end{array}$} & \multirow[t]{2}{*}{ Chi square } & \multirow[t]{2}{*}{$\mathrm{p}$-value } \\
\hline & Poor n(\%) & Good $n(\%)$ & & \\
\hline \multicolumn{5}{|l|}{ Level of education } \\
\hline No formal education & $33(58.9)$ & $23(41.1)$ & & \\
\hline Primary & $131(63.6)$ & $75(36.4)$ & 23.145 & $<0.001$ \\
\hline Secondary & $165(60.0)$ & $110(40.0)$ & & \\
\hline Tertiary & $33(35.1)$ & $61(64.9)$ & & \\
\hline \multicolumn{5}{|l|}{ Occupation } \\
\hline Trading & $232(61.1)$ & $148(38.9)$ & & \\
\hline Artisan & $34(50.7)$ & $33(49.3)$ & 35.317 & $<0.001$ \\
\hline Civil servant & $24(30.8)$ & $54(69.2)$ & & \\
\hline Farming & $14(93.3)$ & $1(6.7)$ & & \\
\hline Others & $58(63.7)$ & $33(36.3)$ & & \\
\hline \multicolumn{5}{|c|}{ Average monthly income } \\
\hline$<10000$ & $249(61.0)$ & $159(39.0)$ & & \\
\hline 10000-19999 & $60(56.1)$ & $47(43.9)$ & 10.813 & 0.013 \\
\hline 20000-29999 & $25(39.7)$ & $38(60.3)$ & & \\
\hline$>=30000$ & $28(52.8)$ & $25(47.2)$ & & \\
\hline \multicolumn{5}{|l|}{ Marital Status } \\
\hline Never married & $86(74.8)$ & $29(25.2)$ & 17.436 & $<0.001$ \\
\hline Ever married & $276(53.5)$ & $240(46.5)$ & & \\
\hline \multicolumn{5}{|l|}{ Religion } \\
\hline Christianity & $142(53.0)$ & $126(47.0)$ & 3.661 & 0.056 \\
\hline Islam & $220(60.6)$ & $143(39.4)$ & & \\
\hline \multicolumn{5}{|l|}{ Respondents } \\
\hline Pregnant & $42(64.6)$ & $23(35.4)$ & & \\
\hline Under-5-caregiver & $310(57.8)$ & $226(42.2)$ & 5.128 & 0.077 \\
\hline Both & $12(40.0)$ & $18(60.0)$ & & \\
\hline
\end{tabular}

3 


\section{Table 8 (on next page)}

Association between respondent characteristics and knowledge of ITN use 
2 Table 8: Association between respondent characteristics and knowledge of ITN use

\begin{tabular}{lcccc}
\hline \multirow{2}{*}{ Characteristics } & \multicolumn{2}{c}{ Knowledge of utilization of } & \multirow{2}{*}{$\mathbf{X}^{\mathbf{2}}$} & \multirow{2}{*}{ p value } \\
& Poor n(\%) & Good n(\%) & & \\
\hline Level of education & $20(35.7)$ & $36(64.3)$ & & \\
No formal education & $74(35.9)$ & $132(64.1)$ & 19.504 & $<0.001$ \\
$\begin{array}{l}\text { Primary } \\
\text { Secondary }\end{array}$ & $88(32.0)$ & $187(68.0)$ & & \\
Tertiary & $11(11.7)$ & $83(88.3)$ & & \\
\hline Occupation & & & & \\
Trading & $128(33.7)$ & $252(66.3)$ & & \\
Artisan & $20(29.9)$ & $47(70.1)$ & & \\
Civil servant & $10(12.8)$ & $68(87.2)$ & 13.627 & 0.009 \\
Farming & $5(33.3)$ & $10(66.7)$ & & \\
Others & $30(33,0)$ & $61(67.0)$ & & \\
\hline Income & & & & \\
$<10000$ & $149(36.5)$ & $259(63.5)$ & & \\
10000-19999 & $27(25.2)$ & $80(74.8)$ & 13.452 & 0.004 \\
20000-29999 & $9(14.3)$ & $54(85.7)$ & & \\
$>=30000$ & $8(15.1)$ & $45(84.9)$ & & \\
\hline Marital Status & & & & \\
Never married & $66(57.4)$ & $49(42.6)$ & 47.592 & $<0.001$ \\
Ever married & $127(24.6)$ & $389(75.4)$ & & \\
\hline Religion & & & & \\
Christianity & $76(28.4)$ & $192(71.6)$ & 1.089 & 0.169 \\
Islam & $117(32.2)$ & $246(67.8)$ & & \\
\hline Respondents & $14(21.5)$ & $51(78.5)$ & & \\
Pregnant & $173(32.3)$ & $363(67.7)$ & 4.811 & 0.090 \\
Under-5-caregiver & $6(20.0)$ & $24(80.0)$ & & \\
Both & & & & \\
\hline
\end{tabular}

3 